\title{
Criptógamos do Parque Estadual das Fontes do Ipiranga, São Paulo, SP. Pteridophyta: 4. Davalliaceae, 19. Schizaeaceae, 23. Vittariaceae e 24. Woodsiaceae
}

\author{
Jefferson Prado ${ }^{1,3}$ e Regina Yoshie Hirai ${ }^{2}$
}

Recebido: 13.07.2010; aceito: 08.12.2010

\begin{abstract}
Cryptogams of "Parque Estadual das Fontes do Ipiranga", São Paulo, SP. Pteridophyta: 4. Davalliaceae, 19. Schizaeaceae, 23. Vittariaceae, and 24. Woodsiaceae). In this work we present a floristic survey of the fern families Davalliaceae, Schizaeaceae, Vittariaceae, and Woodsiaceae occurring in "Parque Estadual das Fontes do Ipiranga" (PEFI). Davalliaceae, Vittariaceae, and Woodsiaceae are, each one, represented in the area by only one genus and one species: Nephrolepis cordifolia (L.) C. Presl, Vittaria lineata (L.) Sm., and Deparia petersenii (Kunze) M. Kato, respectively. This last species occurs in the area as sub spontaneous. There is also Schizaeaceae with two genera and three species: Anemia phyllitidis (L.) Sw., A. raddiana Link, and Lygodium volubile Sw. We also present keys to identify genera and species of Schizaeaceae, as well as description, geographical distribution, and comments for all taxa. Illustrations are presented just for some species.
\end{abstract}

Key words: Atlantic Forest, Lomariopsidaceae, Lygodiaceae, Pteridaceae

RESUMO - (Criptógamos do Parque Estadual das Fontes do Ipiranga, São Paulo, SP. Pteridophyta: 4. Davalliaceae, 19. Schizaeaceae, 23. Vittariaceae e 24. Woodsiaceae). Neste trabalho são apresentados os dados referentes ao levantamento florístico das famílias Davalliaceae, Schizaeaceae, Vittariaceae e Woodsiaceae no Parque Estadual das Fontes do Ipiranga (PEFI). Davalliaceae, Vittariaceae e Woodsiaceae estão representadas na área por um único gênero e uma única espécie cada: Nephrolepis cordifolia (L.) C. Presl, Vittaria lineata (L.) Sm. e Deparia petersenii (Kunze) M. Kato, respectivamente. Esta última espécie ocorre na área como subespontânea. Há também Schizaeaceae com dois gêneros e três espécies: Anemia phyllitidis (L.) Sw., A. raddiana Link e Lygodium volubile Sw. São apresentadas chaves para identificação dos gêneros e espécies de Schizaeaceae, bem como descrições, distribuição geográfica e comentários para todos os táxons. Ilustrações são apresentadas apenas para algumas espécies.

Palavras-chave: Floresta Atlântica, Lomariopsidaceae, Lygodiaceae, Pteridaceae

\section{Introdução}

O presente trabalho é uma continuação do levantamento florístico das samambaias e licófitas do Parque Estadual das Fontes do Ipiranga (PEFI) iniciado por Hoehne et al. (1941). Esse estudo tem sido complementado nos últimos anos com os trabalhos de Prado (2004a, b, c, d, e, f, g, 2006a, b) e Prado \& Hirai (2008).

Davalliaceae, Schizaeaceae, Vittariaceae e Woodsiaceae já foram tratadas por outros autores também para o estado de São Paulo, na forma de floras regionais, como por exemplo: Boldrin \& Prado (2007) e Nóbrega \& Prado (2008), bem como em listas de espécies para determinadas regiões, tais como: Campos do Jordão (Brade 1937), Serra do Cuscuzeiro (Salino 1996), Jacaré-Pepira (Salino \& Joly 2001), Porto Ferreira (Colli et al. 2003), Maçiço da Juréia (Prado 2004h), Vassununga (Colli et al. 2004), Jacupiranga (Salino \& Almeida 2008) e Paranapiacaba (Prado \& Labiak 2009).

O objetivo desse estudo é apresentar o tratamento taxonômico para essas famílias na área do PEFI.

\section{Material e métodos}

O material para este trabalho foi coletado de acordo com as técnicas descritas em Fidalgo \& Bononi

1. Instituto de Botânica, Herbário SP, Caixa Postal 68041, 04045-972 São Paulo, SP, Brasil

2. Curso de Pós-Graduação em Biodiversidade Vegetal e Meio Ambiente, Instituto de Botânica

3. Autor para correspondência: jprado.01@uol.com.br 
(1984) e encontra-se depositado nos Herbários do Instituto de Botânica (SP) e do Departamento de Botânica da Universidade de São Paulo (SPF).

Os dados sobre a caracterização e localização do Parque Estadual das Fontes do Ipiranga (PEFI), bem como o planejamento desta flora, foram apresentados em Melhem et al. (1981) e Milanez et al. (1990).

Segundo a classificação de Smith et al. (2006, 2008), baseada em filogenia molecular, os gêneros Anemia e Lygodium são atualmente reconhecidos como famílias distintas (Anemiaceae e Lygodiaceae, respectivamente), Nephrolepis e Vittaria, por outro lado, estão dentro de Lomariopsidaceae e Pteridaceae, respectivamente. No entanto, como esta flora do PEFI foi iniciada em 2004 e adotou a circunscrição de famílias utilizada por Moran \& Riba (1995), para a Flora Mesoamericana, foi mantido essa mesma circunscrição no presente trabalho.

O número que antecede o nome das famílias, no título deste trabalho corresponde à numeração das famílias apresentadas em Prado (2004a). Foram reunidas quatro famílias nesse estudo por se tratarem de grupos pequenos com uma única espécie cada (Davalliaceae, Vittariaceae e Woodsiaceae), além de Schizaeaceae com apenas três espécies, que geralmente são comuns nas floras regionais de samambaias em áreas de Mata Atlântica.

Os táxons estudados estão apresentados em ordem alfabética de famílias, gêneros e espécies. A abreviação dos nomes dos autores de táxons está de acordo com Pichi-Sermolli (1996).

Foram ilustradas apenas duas das seis espécies, porque dentre todas elas, são as que apresentam maior dificuldade para identificação e, como já comentado, os outros táxons são comuns nas floras regionais de samambaias e encontram-se bem ilustradas.

Material adicional foi utilizado para complementação das descrições, no caso em que determinadas estruturas não estavam presentes no material coletado no PEFI.

\section{Resultados e Discussão}

No primeiro trabalho realizado por Hoehne et al. (1941), para a área do Parque e que envolveu as samambaias, foram registradas as seguintes espécies relacionadas as famílias em estudo: Davallia solida (Forst.) Sw., Nephrolepis cordifolia (L.) C. Presl, Vittaria lineata (L.) Sm., sendo que a primeira delas era cultivada nas estufas e, segundo o autor, originária da Malásia e Polinésia.
No presente levantamento foram encontradas na área do PEFI seis espécies pertencentes à Davalliaceae, Vittariaceae, Woodsiaceae (todas com apenas uma espécie cada) e Schizaeaceae (com três espécies).

Davalliaceae

Plantas terrestres, epífitas ou rupícolas. Caule ereto, decumbente ou longo-reptante, moderadamente compacto a delgado, com escamas. Frondes fasciculadas, cespitosas ou espaçadas entre si; pecíolo contínuo ou articulado com o caule, com 3-6 feixes vasculares na base; lâmina inteira a geralmente 1-pinada, monomorfa a subdimorfa, glabra ou pubescente; nervuras livres. Soros arredondados, às vezes alongados, raramente lineares, abaxiais, medianos a submarginas na extremidade de uma nervura ou sobre a nervura ou em uma comissura inframarginal, com ou geralmente sem paráfises; indúsio de origem abaxial, orbicular, semilunar, reniforme ou orbicular-reniforme com um enseio amplo (conspícuo) ou estreito (inconspícuo); esporângios longo-pedicelados, pedicelo com 2-3 fileiras de células, ânulo longitudinal, interrompido pelo pedicelo; esporos monoletes, sem clorofila.

Segundo Moran (1995a), Davalliaceae apresenta 14 gêneros e aproximadamente 120 espécies, cosmopolitas, distribuídas principalmente nas regiões tropicais e subtropicais.

\section{Nephrolepis Schott}

Plantas terrestres, epífitas ou rupícolas. Caule ereto a reptante, estolonífero ou não, com poucas a muitas raízes fibrosas. Frondes monomorfas, fasciculadas, cespitosas; pecíolo com 3 feixes vasculares na porção basal, contínuo com o caule, glabro ou com escamas; lâmina 1-pinada, glabra, com tricomas e/ou escamas; raque sulcada adaxialmente, com escamas, tricomas ou glabra; pinas alternas, inteiras, glabras a pubescentes, articuladas com a raque; nervuras terminando em hidatódios próximos às margens. Soros arredondados a reniformes, sobre a extremidade das nervuras, submarginais a equidistantes; indúsio reniforme, semilunar ou orbicular-reniforme, peltado ou com um sinus largo ou estreito, glabro ou pubescente; esporos rugosos a tuberculados.

Nephrolepis tem aproximadamente 30 espécies distribuídas em regiões tropicais e subtropicais no mundo todo. É facilmente reconhecido dentro da família por apresentar lâmina 1-pinada, pecíolo contínuo com o caule, caule curto-reptante, bem 
como pelos soros no ápice das nervuras (Moran 1995a). Outra característica que claramente distingue este gênero é as pinas articuladas com a raque, que ao caírem deixam cicatrizes bem evidentes.

$\mathrm{Na}$ atual classificação de Smith (2006, 2008), Nephrolepis pertence a família Lomariopsidaceae.

Nephrolepis cordifolia (L.) C. Presl, Tent. Pterid. 79. 1836 三 Polypodium cordifolium L., Sp. pl. 2: 1089. 1753.

Figura $1 \mathrm{~A}-\mathrm{D}$

Plantas terrestres ou epífitas. Caule ereto, com tubérculos, escamas 2,5-6,0 × 0,5-0,9 mm, castanhas a amareladas, com centro escuro (castanho ou quase negro) quase até as margens ou somente no ponto de inserção, oval-lanceoladas a lineares, peltadas, base irregularmente arredondada e com cílios curtos a longos, margens levemente denticuladas, ápice filiforme, às vezes atenuado. Frondes monomorfas, eretas a pendentes, 43,0-68,0 × 2,7-6,5 cm; pecíolo cilíndrico, sulcado adaxialmente, 3,7-13,5 cm compr, com escamas semelhantes às do caule; lâmina linear, gradualmente estreitando-se para a base e abruptamente para o ápice, 1-pinada, pinas basais mais espaçadas do que as medianas e apicais; raque com escamas 1,2-2,8 × 0,4-1,0 mm, amareladas, castanhoescuras no centro, lineares, ápice longamente filiforme, dispostos ao longo da raque e na base da inserção das pinas abaxialmente e adaxialmente; pinas oblongas, ligeiramente falcadas (com o ápice curvado para cima), as maiores na porção mediana da lâmina 1,5$3,2 \times 0,4-0,9 \mathrm{~cm}$, base assimétrica, lado basiscópico arredondado a cordado, lado acroscópico auriculado sobrepondo-se a raque, margens crenadas, ápice arredondado a levemente agudo; nervuras simples e bifurcadas; hidatódios conspícuos na face adaxial da lâmina, com secreções calcárias e esbranquiçadas, próximo às margens da lâmina. Soros em posição submarginal; indúsio reniforme a semilunar, com sinus amplo, margens inteiras.

Material examinado: 6-X-2003, J. Prado \& D.M. Vital 1430 (SP, SPF); 26-IV-2010, J. Prado \& R.Y. Hirai 2137 (SP).

Material adicional examinado: BRASIL. SÃo PAULO: Serra do Mar, s.d., M. Wacket s.n. (SP21239).

Distribuição geográfica: Ásia, sudeste dos Estados Unidos, México, Guatemala, El Salvador, Honduras, Nicarágua, Panamá, Grandes e Pequenas Antilhas, Guianas, Venezuela, Colômbia, Galápagos, Peru e Brasil - Pernambuco, Bahia, Minas Gerais, Espírito Santo, Rio de Janeiro, São Paulo, Paraná, Santa
Catarina e Rio Grande do Sul.

Nephrolepis cordifolia é caracterizada por apresentar pinas basais mais espaçadas do que as medianas e apicais, pelas pinas oblongas, ligeiramente falcadas, margens crenadas, base assimétrica, isto é, o lado basiscópico arredondado a cordado e o acroscópico auriculado sobrepondo-se a raque.

Esta espécie foi encontrada na área do PEFI como terrestre e epífita na base de tronco de palmeiras. Apenas frondes estéreis foram observadas na área do Parque.

\section{Schizaeaceae}

Plantas terrrestres. Rizoma ereto a reptante, com tricomas ou escamas. Frondes cespitosas ou fasciculadas, eretas ou escandentes, monomorfas a parcialmente (hemidimorfas) ou totalmente dimorfas, com crescimento determinado ou indeterminado; pecíolo contínuo com o caule; lâmina inteira, filiforme, flabelada, dicotômica ou 1-3-pinada, glabra ou pubescente; nervuras livres ou areoladas. Soros formados em panículas, digitadas, subdigitadas, pinatífidas ou pinadas ou segmentos modificados na margem da lâmina; indúsio ausente ou esporângios protegidos pela margem da lâmina modificada; esporângios dispostos em 2 fileiras, sobre o último segmento das pinas férteis ou sobre lobos marginais das pínulas, solitários, sésseis, obovóides ou piriformes; ânulo apical não interrompido pelo pedicelo; esporos triletes ou monoletes, sem clorofila.

Esta família apresenta cinco gêneros e aproximadamente 170 espécies, sendo que a característica marcante nela é a presença de esporângios obovóides ou piriformes, sésseis, com ânulo apical (Moran 1995b).

Segundo a classificação recente de Smith (2006, 2008), Schizaeaceae foi separada em três famílias distintas: Anemiaceae (com um único gênero Anemia, ca. 100 spp.), Lygodiaceae (com um único gênero Lygodium, ca. 25 spp.) e Schizaeaceae (com dois gêneros, Actinostachys e Schizaea, ca. 30 spp.).

\section{Chave para os gêneros de Schizaeaceae}

1. Frondes com crescimento determinado, parcial ou totalmente dimorfas; esporângios dispostos em panículas.................................................. Anemia

1. Frondes com crescimento indeterminado, monomorfas; esporângios dispostos em duas fileiras, sobre lobos marginais das pínulas .......... Lygodium 


\section{Anemia Sw.}

Plantas terrestres ou rupícolas. Rizoma curtoreptante, decumbente ou ereto, com tricomas pluricelulares, curtos a longos. Frondes parcial (hemidimorfas) ou totalmente dimorfas, com crescimento determinado, pinas férteis modificadas em panículas, pecioluladas, frequentemente eretas, com tecido laminar muito reduzido ou ausente, inseridas abaixo da base ou na base da lâmina estéril; pecíolo geralmente sulcado na superfície adaxial; raque levemente sulcada adaxialmente ou não sulcada; lâmina estéril oval a deltóide, pinatífida a 3-pinada, quando pinada com 4-13 pares de pinas, às vezes apenas pinatilobada, muito raramente simples, ápice pinatífido ou às vezes com uma pina terminal conforme; nervuras livres ou areoladas, sem vênulas livres inclusas nas aréolas; esporângios sésseis, subglobosos ou ovais, dispostos em duas fileiras sobre o último segmento das pinas férteis; esporos triletes e ornamentados com sulcos paralelos e proeminentes, equinados, rugoso-reticulados ou com espículas.

Anemia apresenta cerca de 100 espécies e a maioria delas distribui-se na região neotropical e apenas dez espécies são encontradas na África e sul da Índia. O Brasil tem ca. 70 espécies e é o centro de diversidade para o gênero, seguido pelo México, com 20 espécies (Moran \& Mickel 1995).

Chave para as espécies de Anemia

1. Lâmina estéril 1-pinada, com 4-8 pares de pinas; nervuras areoladas A. phyllitidis

1. Lâmina estéril 1-pinado-pinatissecta a 1 pinado-pinatífida, às vezes 2-pinada na base, com 10-13 pares de pinas; nervuras livres A. raddiana

Anemia phyllitidis (L.) Sw., Syn. Fil.: 155. 1806 $\equiv$ Osmunda phyllitidis L., Sp. pl. 2: 1064. 1753.

Plantas terrestres. Rizoma ereto, densamente revestido por tricomas castanhos a castanho-escuros (quase negros), 2,5-5,5 mm compr. Frondes 40-90 cm compr., hemidimorfas; pecíolo 31,5-58,0 cm compr., castanho-claro a amarelado, sulcado adaxialmente, com tricomas castanhos, semelhantes aos do rizoma; lâmina estéril 14,5-29,5 × 14,0-20,0 cm, deltóide, 1-pinada, raque com tricomas castanhos, semelhantes aos do rizoma, com 4-8 pares de pinas inteiras; pinas estéreis 7,2-11,5 × 2,2-3,1 cm, lanceoladas, opostas, curto-pecioluladas, base arredondada, margens serreadas, ápice acuminado, pina apical geralmente conforme, nervuras areoladas; tricomas castanhos, semelhantes aos do rizoma, sobre a costa, nervuras e tecido laminar, 0,4-2,0 $\mathrm{mm}$ compr., esparsos abaxialmente sobre a costa, nervuras e tecido laminar, adaxialmente conspícuo sobre a costa, ausente nas nervuras e tecido laminar; pinas férteis com tecido laminar reduzido, eretas, emergindo na mesma altura do primeiro par de pinas estéreis, geralmente maiores que a lâmina estéril.

Material examinado: 30-VI-1938, O. Handro s.n. (SP44451, SPF66162); XII-1954, O. Handro 424 (SP); 10-VIII-1967, R. Faria 33, 34 (SP); 2-IV-1974, J.A. Corrêa 14 (SP); 9-IV-1974, J.A. Corrêa 5, 11 (SP); 30-IV-1974, J.A. Corrêa 44 (SP); 14-V-1974, J.A. Corrêa 56 (SP); 21-II-1976, G. Davidse \& W.G. D'Arcy 10429 (SP); 21-XI-1977, H. Makino 102 (SP); 6-III-1978, A. Tosta Silva 67 (SP); 21-XI-1980, N.A. Rosa \& J.M. Pires 3823 (SP); 10-VI-2003, J. Prado \& G.B. Silva 1417 (SP); 6-X-2003, J. Prado \& D.M. Vital 1427 (SP, SPF).

Distribuição geográfica: sul do México, El Salvador, Nicarágua, Grandes Antilhas, Suriname, Guiana, Venezuela, Colômbia, Equador, Peru, Bolívia, Paraguai, Argentina, Uruguai e Brasil - Ceará, Bahia, Acre, Goiás, Distrito Federal, Mato Grosso, Minas Gerais, Espírito Santo, Rio de Janeiro, São Paulo, Paraná, Santa Catarina e Rio Grande do Sul.

Anemia phyllitidis difere de Anemia raddiana pelas características utilizadas na chave. É uma espécie extremamente comum na área do PEFI, encontrada nos barrancos próximos as áreas com vegetação bastante alterada. Pode ser facilmente reconhecida pelas pinas inteiras, lanceoladas e com nervuras areoladas.

Anemia raddiana Link, Hort. Berol. 2: 144. 1833. Figura $1 \mathrm{E}-\mathrm{H}$

Plantas terrestres. Rizoma ereto, densamente revestido por tricomas castanho-claros a castanhos, 3,0-5,0 $\mathrm{mm}$ compr. Frondes $45-96 \mathrm{~cm}$ compr., hemidimorfas; pecíolo 21,5-60,0 cm compr., amarelado, castanho-claro na base, sulcado adaxialmente, com tricomas castanhos, semelhantes aos do rizoma; lâmina estéril 23,5-29,5 × 13,0$18,5 \mathrm{~cm}$, deltóide, 1-pinado-pinatissecta na base a 1-pinado-pinatífida em direção ao ápice, às vezes 2-pinada na base, raque com tricomas castanhos, semelhantes aos do rizoma, com 10-13 pares, pinas estéreis, $6,0-9,5 \times 2,0-4,5 \mathrm{~cm}$, oval-lanceoladas, levemente alternas a opostas, pecioluladas, base obtusa, margens inteiras, levemente revolutas, ápice agudo, pina apical levemente pinatífida, nervuras livres, bifurcadas; tricomas castanhos a hialinos, 


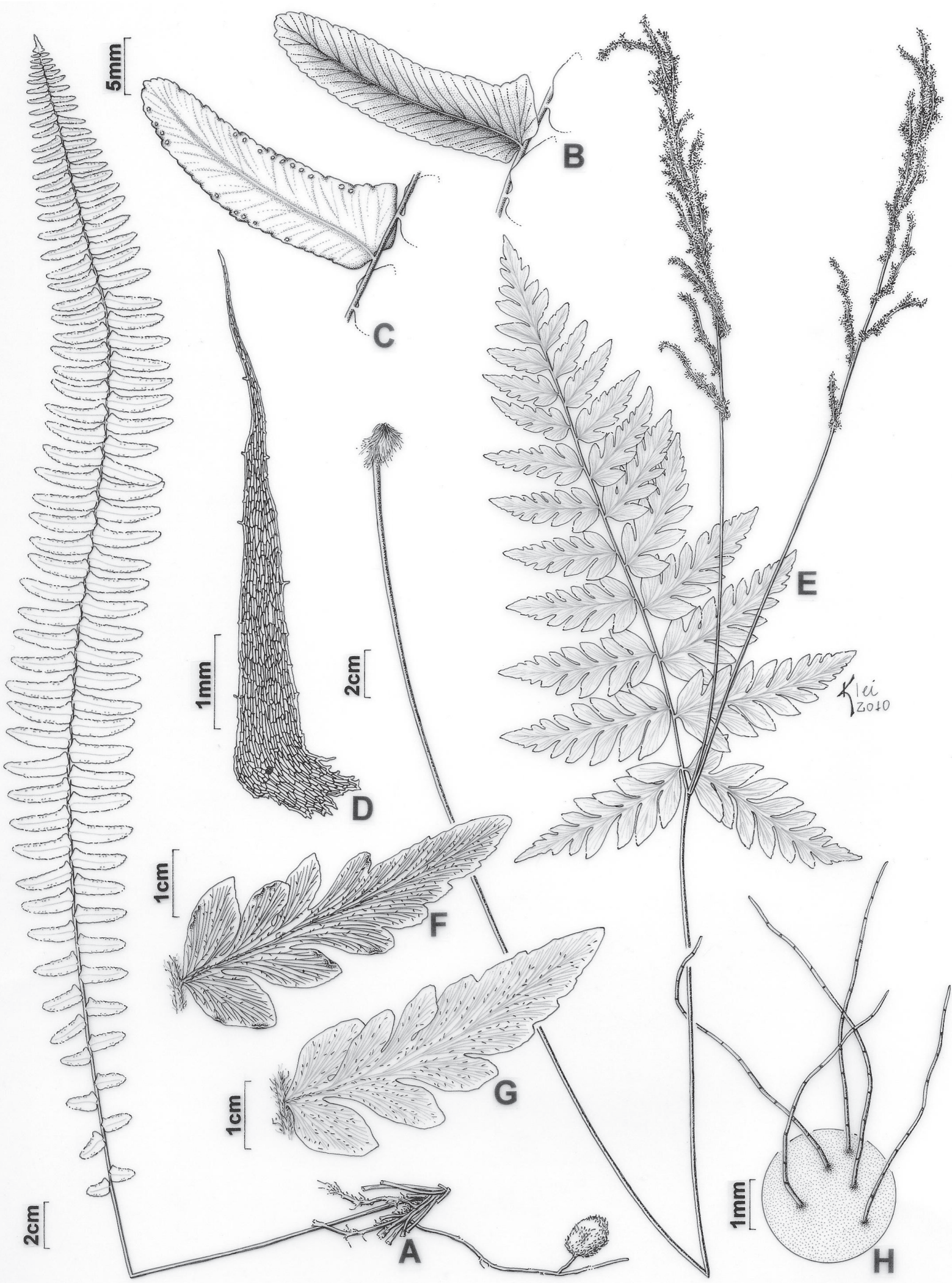

Figura 1. A-D. Nephrolepis cordifolia (Prado \& Vital 1430). A. Hábito mostrando um tubérculo. B. Detalhe das nervuras de uma pina estéril, face abaxial. C. Detalhe da face adaxial de uma pina estéril com hidatódios. D. Escama do caule. E-H. Anemia raddiana (Handro 2167). E. Fronde mostrando as pinas férteis e estéreis. F. Detalhe das nervuras e tricomas da pina estéril, face abaxial. G. Detalhe das nervuras e tricomas da pina estéril, face adaxial. H. Tricoma da base do pecíolo.

Figure 1. A-D. Nephrolepis cordifolia (Prado \& Vital 1430). A. Habit showing a tuber. B. Detail of the veins of the sterile pinna, abaxial surface. C. Detail of the adaxial surface of the sterile pinna with hydathodes. D. Steem scale. E-H. Anemia raddiana (Handro 2167). E. Frond showing fertile and sterile pinnae. F. Detail of the veins and hairs on the sterile pinna, abaxial surface. G. Detail of the veins and hairs on the sterile pinna, adaxial surface. H. Hair of the stipe base. 
semelhantes aos do rizoma, 0,2-2,0 $\mathrm{mm}$ compr., abaxialmente sobre a costa e nervuras, adaxialmente sobre a costa, nervuras e tecido laminar; pinas férteis com tecido laminar reduzido, eretas, emergindo 2,04,0 $\mathrm{mm}$ abaixo do primeiro par de pinas estéreis, maiores que a lâmina estéril.

Material examinado: 18-V-1971, O. Handro 2167 (SP, SPF); 26-IV-2010, J. Prado \& R.Y. Hirai 2136 (SP, SPF).

Distribuição geográfica: Endêmica do Sudeste e Sul do Brasil - Minas Gerais, Rio de Janeiro, São Paulo, Paraná, Santa Catarina e Rio Grande do Sul.

A espécie mais semelhante a Anemia raddiana é A. ferruginea Kunth var. ferruginea, que não ocorre na área do PEFI. Difere por apresentar tricomas maiores (ca. 6,0 mm compr. vs. 0,2-2,0 mm compr.) abaxialmente sobre a costa e nervuras e adaxialmente sobre a costa, nervuras e tecido laminar.

\section{Lygodium $\mathrm{Sw}$}

Plantas geralmente trepadeiras, às vezes terrestres. Caule reptante, com tricomas negros. Frondes monomorfas, escandentes, trepadeiras, com crescimento indeterminado; pecíolo cilíndrico, às vezes com tricomas; lâmina 2-3-pinada; raque volúvel; pinas alternas, curto-pecioluladas, pseudodicotomicamente ramificada, com uma gema na axila de cada pina, simples, lobadas, radialmente lobadas ou pinadas; pínulas subdimorfas; nervuras livres ou areoladas, sem vênulas livres inclusas nas aréolas; esporângios em duas fileiras, formados sobre lobos marginais das pínulas, protegidos por indúsios falsos, valvados; esporos triletes, verrucosos ou reticulados.

Há aproximadamente 35 espécies de Lygodium, que é um gênero pantropical, estendendo-se a zonas temperadas ao leste dos Estados Unidos, África do Sul, Japão e Nova Zelândia. Além disso, é um gênero incomum de samambaia por se tratar de uma planta trepadeira com crescimento indeterminado (Moran $1995 \mathrm{c})$

Lygodium volubile Sw., J. Bot. (Schrad.) 1801: 304. 1803.

Plantas terrestres ou trepadeiras. Rizoma não observado. Frondes com tricomas na raque, 0,3$0,7 \mathrm{~mm}$ compr., hialinos, levemente castanhoavermelhados, aciculares, multicelulares; lâmina 2-pinada; pinas opostas, pecioluladas; pínulas geralmente oval-lanceoladas a lanceoladas, pecioluladas, base arredondada ou levemente auriculada em um dos lados ou em ambos os lados, margens denteadas, ápice agudo a obtuso, às vezes atenuado ou arredondado, com tricomas semelhantes aos da raque, abaxialmente na costa, nervuras e tecido laminar, adaxialmente esparsos sobre as nervuras e tecido laminar; pínulas proximais e distais de dimensões semelhantes, pínulas estéreis 1,9-5,0 × 0,9-1,4 cm, peciólulo 0,1-0,4 cm compr., pínulas férteis $2,8-6,5 \times 1,0-1,5 \mathrm{~cm}$, peciólulo $0,1-$ $0,7 \mathrm{~cm}$ compr., nervuras livres, furcadas, terminando no interior de dentes nas margens das pínulas; esporângios dispostos em espigas, nas margens das pínulas, em duas fileiras, uma de cada lado da espiga, cada um protegido por um falso indúsio formado pelo tecido laminar recurvado, sésseis, com tricomas. Material examinado: 24-VIII-1979, M.R.R. Melo 142 (SP); 6-X-2003, J. Prado \& D.M. Vital 1431 (SP); 26-III-2004, J. Prado et al. 1563 (SP, SPF).

Distribuição geográfica: México, Belize, Guatemala, Honduras, Nicarágua, Costa Rica, Panamá, Cuba, Jamaica, Trinidad, Colômbia, Venezuela, Guiana Francesa, Suriname, Guiana, Equador, Peru, Bolívia, Argentina e Brasil - Pernambuco, Bahia, Maranhão, Pará, Amazonas, Acre, Minas Gerais, Rio de Janeiro, São Paulo, Paraná, Santa Catarina e Rio Grande do Sul.

No Brasil ocorrem apenas duas espécies desse gênero. Lygodium volubile que é distinta de $L$. venustum Sw. (ausente na área do PEFI) por apresentar pínulas com aurículas conspícuas na base, sendo que a aurícula distal é mais curta do que a proximal (Mickel \& Smith 2004).

Esta espécie é comum na área do PEFI como plantas terrestres e trepadeiras, crescendo sobre fanerógamas. Trata-se de uma planta com hábito trepador facilmente visível na mata.

\section{Vittariaceae}

Plantas epífitas, às vezes rupícolas ou terrestres. Caule reptante, subereto ou ereto, com escamas clatradas. Frondes cespitosas ou separadas entre si, eretas ou pendentes, monomorfas; pecíolo contínuo com o caule, com 1 feixe vascular na base; lâmina inteira ou dicotomicamente dividida na região do ápice, lanceolada, oblanceolada, elíptica ou oval, glabra, com idioblastos conspícuos na epiderme adaxial; nervuras geralmente areoladas ou livres. Soros lineares, a alongados, sobre a face abaxial da lâmina, com ou sem paráfises, sem indúsio, esporângios globosos, numerosos, pedicelo com 1-2 fileiras de células, ânulo longitudinal interrompido 
pelo pedicelo, estômio com 4 células; esporos triletes ou monoletes, sem clorofila.

Segundo Moran (1995d), esta família apresenta cinco gêneros e aproximadamente 100 espécies, pantropicais, com algumas poucas espécies em regiões temperadas. São plantas predominantemente epífitas, caracterizadas por apresentarem escamas do caule clatradas, frondes simples e com soros expandidos ou lineares na lâmina foliar.

Crane (1997), baseado em estudos moleculares e morfologia, reconheceu 10 gêneros monofiléticos na família.

Segundo a atual classificação de Smith (2006, 2008), as espécies pertencentes a essa família formam um grupo monofilético dentro de Pteridaceae. Esse grupo atualmente é reconhecido como samambaias vitarióides.

\section{Vittaria Sm.}

Plantas epífitas, com mais de $5 \mathrm{~cm}$ compr. Caule curto-reptante a subereto, com poucas raízes. Frondes pendentes; pecíolo muito reduzido ou ausente, esverdeado, paleáceo ou castanho, aplanado ou cilíndrico; lâmina inteira, linear a estreitamente elíptica, coriácea a cartácea, glabra; nervuras areoladas, geralmente 1 fileira de aréolas alongadas entre a costa e a margem da lâmina, sem vênulas livres inclusas nas aréolas. Soros lineares, submarginais, paralelos à margem da lâmina, com paráfises simples, furcadas, célula apical das paráfises alargada ou não; esporos triletes ou monoletes, geralmente lisos ou com depósitos esféricos espalhados na superfície.

Vittaria apresenta ca. 50 espécies e é encontrado nos trópicos. O gênero se distingue dos outros gêneros na família por apresentar soros lineares nas margens da lâmina (Moran 1995d).

Vittaria lineata (L.) Sm., Mém. Acad. Roy. Sci. (Turin) 5: 421, tab.9, fig. 5. $1793 \equiv$ Pteris lineata L., Sp. pl. 2: 1073. 1753.

Plantas epífitas. Caule curto-reptante, compacto, com escamas 2,0-3,4 $\mathrm{mm} \times 0,1-0,3$ $\mathrm{mm}$, lineares, basifixas, margens denteadas, ápice filiforme, castanho-escuras (quase negras). Frondes monomorfas; pecíolo achatado, verde, não sulcado; lâmina 11,0-74,5 cm × 1,5-2,5 mm, graminiforme, linear, superfícies adaxial e abaxial glabras, margens revolutas; nervuras não visíveis. Soros lineares, contínuos, localizados em canaletas profundas próximas da margem da lâmina, paráfises hialinas, levemente castanhas, filiformes, com uma célula apical não expandida, ou apenas levemente; esporos reniformes, monoletes.

Material examinado: 18-IX-1928, F.C. Hoehne \& M. Kuhlmann s.n. (SP26515); 15-X-1940, O. Handro s.n. (SP45720).

Distribuição geográfica: Sudeste dos Estados Unidos, México, Guatemala, Belize, Honduras, Nicarágua, Costa Rica, Panamá, Grandes e Pequenas Antilhas, Trinidad, Colômbia, Venezuela, Guianas, Equador, Peru, Bolívia, Paraguai, Uruguai e Brasil - Ceará, Pernambuco, Bahia, Maranhão, Amapá, Pará, Amazonas, Acre, Mato Grosso, Mato Grosso do Sul, Minas Gerais, Espírito Santo, Rio de Janeiro, São Paulo, Paraná, Santa Catarina e Rio Grande do Sul.

Esta espécie é facilmente reconhecida por apresentar paráfises filiformes, com uma célula apical não expandida, ou apenas levemente, bem como pelos esporos monoletes. As outras duas espécies que ocorrem no estado de São Paulo, mas não na área do PEFI são $V$. graminifolia Kaulf. e $V$. costata Kunze. A primeira difere por apresentar paráfises com célula apical expandida e esporos triletes e a segunda por apresentar lâmina com 0,6-1,5 cm larg. (Moran 1995d).

\section{Woodsiaceae}

Plantas terrestres ou rupícolas. Rizoma ereto a reptante, com escamas, estolonífero ou não. Frondes estéreis e férteis monomorfas ou dimorfas (em Onocleopsis), contínuas com o caule; pecíolo com 2 feixes vasculares na base; pinas contínuas com a raque; raque e costa sulcados, sulcos decorrentes ou não, contínuos ou interrompidos, nervuras livres ou areoladas, sem vênulas livres inclusas nas aréolas. Soros abaxiais, arredondadas a lineares, sem paráfises, com indúsio arredondado a linear; esporângios com ânulo vertical interrompido pelo pedicelo; pedicelo do esporângio com 2 ou 3 fileiras de células abaixo da cápsula; esporos sem clorofila, monoletes.

Woodsiaceae apresenta ca. de 500 espécies e tem distribuição cosmopolita. Esta família é fracamente definida porque difere de Dryopteridaceae apenas por uma única característica, que é a presença de dois feixes vasculares vs. três ou mais feixes vasculares na base do pecíolo. (Moran 1995e).

\section{Deparia Hook. \& Grev.}

Plantas terrestres. Rizoma reptante, estolões ausentes. Frondes monomorfas; pecíolo 1/3-2/3 o comprimento da lâmina, feixes vasculares laterais, lunados em corte transversal; lâmina elíptica a oval- 
lanceolada, 1-pinado-pinatífida (pinatífida a 3-pinadopinatífida), gradualmente reduzida distalmente a um ápice pinatífido; pinas não articuladas a raque, margens dos segmentos inteiras, crenuladas ou serreadas; pinas proximais (vários pares) reduzidas ou não, sésseis, equilaterais; costa adaxialmente com sulcos rasos, sulcos não contínuos com os sulcos da raque; indumento sobre a raque e costa (em ambas as faces) de tricomas multicelulares; nervuras livres, simples ou furcadas. Soros sobre as nervuras, alongados, quase retos ou curvos na terminação distal, indúsio linear, preso lateralmente, persistente; esporos tuberculados, rugosos ou equinados.

Segundo Kato (1993), há ca. de 50 espécies no gênero e ocorrem na América do Norte, Ásia, África tropical, incluindo Madagascar, ilhas do Pacífico e Austrália.

No Brasil este gêneroocorrecomo subespontâneo.

Deparia petersenii (Kunze) M. Kato, Bot. Mag. (Tóquio) 90: 37. $1977 \equiv$ Asplenium petersenii Kunze, Analecta Pteridogr.: 24. 1837.

Plantas terrestres. Rizoma longo-reptante, com escamas 5,5-7,0 × 0,5-1,5 mm, lanceoladas, castanhas, base truncada, margens inteiras, ápice acuminado a filififormes. Frondes 60,5-101,0 $\times$ 19,5-23,0 cm; pecíolo 25,0-47,0 cm compr., sulcado adaxialmente; lâmina oval, 1-pinado-pinatissecta na base, 1-pinado-pinatífida em direção ao ápice, ápice pinatífido; pinas oblongo-lanceoladas, pecioluladas a sésseis, 11,2-16,0 × 1,6-3,1 cm, ápice atenuado; segmentos oblongos, margens inteiras a levemente denteadas, ápice arredondado a obtuso; indumento formado por escamas e tricomas, as escamas principalmente na base do pecíolo semelhantes às do rizoma, escamas 0,5-1,0 $\times 0,1-0,2 \mathrm{~mm}$, filiformes, hialinas a castanho-avermelhadas, às vezes, castanho-escuras (negras), dispostas abaxialmente e adaxialmente na raque, costa e cóstula, tricomas 0,3-0,5 mm compr., hialinos a levemente castanhoavermelhados, aciculares, multicelulares, dispostos abaxialmente e adaxialmente sobre a raque, costa, cóstula e nervuras, mais esparsos sobre o tecido laminar; nervuras simples e bifurcadas. Soros curtos, 2,0-3,0 mm compr., indúsio com tricomas, margem fimbriada.

Material examinado: 10-X-1970, O. Handro 2150 (SPF); 20-XII-2005, J. Prado \& G.B. Silva 1614 (SP, SPF).

Distribuição geográfica: nativa do Sudeste da Ásia e introduzida no Brasil - Minas Gerais, Espírito
Santo, Rio de Janeiro, São Paulo, Paraná, Santa Catarina e Rio Grande do Sul.

Deparia petersenii é a única espécie do gênero que ocorre no Brasil. Esta espécie foi introduzida. No entanto, ocorre como subespontânea em diversas localidades, inclusive em áreas de preservação, como no PEFI. Pode ser facilmente reconhecida pelo denso indumento de tricomas hialinos em ambas as faces da lâmina e pelos soros curtos e com indúsio piloso.

\section{Agradecimentos}

Ao CNPq pela concessão da Bolsa de Produtividade em Pesquisa e auxílio para este projeto (processo 300843-93-3). Gostaríamos de agradecer ao Dr. John T. Mickel, do Jardim Botânico de Nova York, por ter fornecido aos autores um catálogo para o gênero Anemia, que permitiu a identificação das espécies aqui apresentadas.

\section{Literatura citada}

Boldrin, A.H.L. \& Prado, J. 2007. Pteridófitas terrestres e rupícolas do Forte dos Andradas, Guarujá, São Paulo, Brasil. Boletim de Botânica da Universidade de São Paulo 25: 1-69.

Brade, A.C. 1937. Excursão a Campos do Jordão. Rodriguésia 9: 113-117.

Colli, A.M.T., Salino, A., Souza, S.A., Lucca, A.L. \& Silva, R.T. 2004. Pteridófitas do Parque Estadual da Vassununga, Santa Rita do Passa Quatro (SP), Brasil, Glebas Capetinga Leste e capetinga Oeste. Revista do Instituto Florestal 16: 25-30.

Colli,A.M.T.,Souza, S.A., \& Silva, R.T. 2003. Pteridófitas do Parque Estadual de Porto Ferreira (SP), Brasil. Revista do Instituto Florestal 15: 29-35.

Crane, E.H. 1997. A revised circumscription of the genera of the fern family Vittariaceae. Systematic Botany 22: 509-517.

Fidalgo, O. \& Bononi, V.L.R. (coords.). 1984. Técnicas de coleta, preservação e herborização de material botânico. Manual 4. Instituto de Botânica, São Paulo.

Hoehne, F.C., Kuhlmann, M. \& Handro, O. 1941. O Jardim Botânico de São Paulo. Secretaria da Agricultura, Indústria e Comércio, Departamento de Botânica do Estado, São Paulo.

Kato, M. 1993. Deparia Hook. \& Grev. In: N.R. Morin (ed.). Flora of North America north of Mexico. Pteridophytes and gymnosperms. 
Oxford University Press, New York, v. 2, pp. 254-255.

Melhem, T.S., Giulietti, A.M., Forero, E., Barroso, G.M., Silvestre, M.S.F., Jung, S.L., Makino, H., Melo, M.M.R.F., Chiea, S.C., Wanderley, M.G.L., Kirizawa, M. \& Muniz, C. 1981. Planejamento para elaboração da "Flora Fanerogâmica da Reserva do Parque Estadual das Fontes do Ipiranga (São Paulo, Brasil)". Hoehnea 9: 63-74.

Mickel, J.T. \& Smith, A.R. 2004. The Pteridophytes of Mexico. Mexico. Memoirs of the New York Botanical Garden 88: 1-1055.

Milanez, A.I., Bicudo, C.E.M., Vital, D.M. \& Grandi, R.A.P. 1990. Criptógamos do Parque Estadual das Fontes do Ipiranga, São Paulo, SP: Planejamento. Hoehnea 17: 43-49.

Moran, R.C. 1995a. Davalliaceae. In: R.C. Moran \& R. Riba (eds.). Psilotaceae a Salviniaceae. In: G. Davidse, M.S. Sousa \& S. Knapp (eds.). Flora Mesoamericana. Universidad Nacional Autónoma de México, Ciudad de México, v. 1, pp. 285-286.

Moran, R.C. 1995b. Schizaeaceae. In: R.C. Moran \& R. Riba (eds.). Psilotaceae a Salviniaceae. In: G. Davidse, M.S. Sousa \& S. Knapp (eds.). Flora Mesoamericana. Universidad Nacional Autónoma de México, Ciudad de México, v. 1, pp. 52.

Moran, R.C. 1995c. Lygodium. In: R.C. Moran \& R. Riba (eds.). Psilotaceae a Salviniaceae. In: G. Davidse, M.S. Sousa \& S. Knapp (eds.). Flora Mesoamericana. Universidad Nacional Autónoma de México, Ciudad de México, v. 1, pp. 56-57.

Moran, R.C. 1995d. Vittariaceae. In: R.C. Moran \& R. Riba (eds.). Psilotaceae a Salviniaceae. In: G. Davidse, M.S. Sousa \& S. Knapp (eds.). Flora Mesoamericana. Universidad Nacional Autónoma de México, Ciudad de México, v. 1, pp. 145-150.

Moran, R.C. 1995e. Woodsiaceae. In: R.C. Moran \& R. Riba (eds.). Psilotaceae a Salviniaceae. In: G. Davidse, M.S. Sousa \& S. Knapp (eds.). Flora Mesoamericana. Universidad Nacional Autónoma de México, Ciudad de México, v. 1, pp. 227.

Moran, R.C. \& Mickel, J.T. 1995. Anemia. In: R.C. Moran \& R. Riba (eds.). Psilotaceae a Salviniaceae. In: G. Davidse, M.S. Sousa \& S. Knapp (eds.). Flora Mesoamericana. Universidad Nacional Autónoma de México, Ciudad de México, v. 1, pp. 53-56.
Moran, R.C. \& Riba, R. 1995. Psilotaceae a Salviniaceae. In: G. Davidse, M.S. Sousa \& S. Knapp (eds.). Flora Mesoamericana. Universidad Nacional Autónoma de México, Ciudad de México, v. 1, pp. 1-470.

Nóbrega, G.A. \& Prado, J. 2008. Pteridófitas da vegetação nativa do Jardim Botânico Municipal de Bauru, Estado de São Paulo, Brasil. Hoehnea 35: 7-55.

Pichi-Sermolli, R.E.G. 1996. Authors of scientific names in Pteridophyta. Royal Botanic Gardens, Kew.

Prado, J. 2004a. Criptógamos do Parque Estadual das Fontes do Ipiranga, São Paulo, SP. Pteridophyta: chave para as famílias; 2. Blechnaceae. Hoehnea 31: 1-10.

Prado, J. 2004b. Criptógamos do Parque Estadual das Fontes do Ipiranga, São Paulo, SP. Pteridophyta: 6. Dicksoniaceae. Hoehnea 31: 239-242.

Prado, J. 2004c. Criptógamos do Parque Estadual das Fontes do Ipiranga, São Paulo, SP. Pteridophyta:14. Ophioglossaceae. Hoehnea 31: 171-174.

Prado, J. 2004d. Criptógamos do Parque Estadual das Fontes do Ipiranga, São Paulo, SP. Pteridophyta:17.Pteridaceae.Hoehnea 31:39-49.

Prado, J. 2004e. Criptógamos do Parque Estadual das Fontes do Ipiranga, São Paulo, SP. Pteridophyta: 8. Gleicheniaceae. Hoehnea 31: 33-37.

Prado, J. 2004f. Criptógamos do Parque Estadual das Fontes do Ipiranga, São Paulo, SP. Pteridophyta: 5. Dennstaedtiaceae. Hoehnea 31: 11-22.

Prado, J. 2004g. Criptógamos do Parque Estadual das Fontes do Ipiranga, São Paulo, SP. Pteridophyta: 15. Osmundaceae. Hoehnea 31: 93-96.

Prado, J. 2004h. Pteridófitas do Maciço da Juréia. In: Marques, O.A.V. \& Duleba, W. (eds.), Estação Ecológica Juréia-Itatins. Ambiente físico, flora e fauna. Holos Editora, Ribeirão Preto, São Paulo, pp. 139-151.

Prado, J. 2006a. Criptógamos do Parque Estadual das Fontes do Ipiranga, São Paulo, SP. Pteridophyta: 18. Salviniaceae. Hoehnea 33: 107-110.

Prado, J. 2006b. Criptógamos do Parque Estadual das Fontes do Ipiranga, São Paulo, SP. Pteridophyta:12. Lophosoriaceae. Hoehnea 33: 123-126.

Prado, J. \& Hirai, R.Y. 2008. Criptógamos do Parque Estadual das Fontes do Ipiranga, São Paulo, SP. Pteridophyta: 13. Lycopodiaceae e 20. Selaginellaceae. Hoehnea 35: 543-552.

Prado, J. \& Labiak, P.H. 2009. Pteridófitas. In: M.I.M.S. Lopes, M. Kirizawa \& M.M.R.F. 
Melo (orgs.). Patrimônio da Reserva Biológica do Alto da Serra de Paranapiacaba: a antiga Estação Biológica do Alto da Serra. Instituto de Botânica, São Paulo, pp. 269-289.

Salino, A. 1996. Levantamento das Pteridófitas da Serra do Cuscuzeiro, Analândia, SP, Brasil. Revista Brasileira de Botânica 19: 173-178.

Salino, A. \& Almeida, T.E. 2008. Pteridófitas do Parque Estadual de Jacupiranga, SP, Brasil. Acta Botanica Brasilica 22: 983-991.

Salino, A. \& Joly, C.A. 2001. Pteridophytes of three remnants of gallery forest in the Jacaré-Pepira river basin, São Paulo State, Brazil. Boletim do Herbário Ezechias Paulo Heringer 8: 5-15.

Smith, A.R., Pryer, K.M., Schuettpelz, E., Korall, P., Schneider, H. \& Wolf, P.G. 2006. A classification for extant ferns. Taxon 55: 705-731.

Smith, A.R., Pryer, K.M., Schuettpelz, E., Korall, P., Schneider, H. \& Wolf, P.G. 2008. Fern classification. In: T.A. Ranker \& C.H. Haufler (eds.). Biology and evolution of ferns and lycophytes. Cambridge University Press, Cambridge, pp. 417-467. 